\title{
Salvage chemotherapy for hormone-refractory prostate cancer: Association of Adriamycin and ifosfamide
}

\author{
MAUD TOULMONDE, PASCAL DÉMOLIS and NADINE HOUÉDÉ \\ Department of Medical Oncology, Institut Bergonié, Comprehensive Cancer Center, 33076 Bordeaux Cedex, France
}

Received May 13, 2010; Accepted July 28, 2010

DOI: $10.3892 / \mathrm{etm} .2010 .138$

\begin{abstract}
Prostate carcinoma is the most common cancer in men. Hormone-resistance is the natural history of this metastatic disease and requires the use of docetaxel as the standard chemotherapy. At present, there is no approved second-line treatment. Here, we report a combination of treatment with Adriamycin and ifosfamide in a series of 7 relatively young patients with an average age of 57 years at the time of diagnosis. Chemotherapy was administered over 3 days with the following schedule: $20 \mathrm{mg} / \mathrm{m}^{2}$ Adriamycin per day and $1-1.5 \mathrm{mg} / \mathrm{m}^{2}$ ifosfamide per day, in association with Uromitexan. Treatment was repeated every 3 weeks. Three biological responses, one $\mathrm{CT}$ scan response, one bone scan response and two CT scan stabilizations, were obtained. Mean survival following this combination was 6.6 months, and over 26 months after first-line chemotherapy. Tolerance was good with the use of granulocyte-colony stimulating factors. Our observations clearly show that the use of this type of salvage therapy for relatively young patients in good physical condition should be further assessed in a clinical trial, particularly when different lines of chemotherapy are required.
\end{abstract}

\section{Introduction}

Prostate cancer, the most common malignancy in men and the second cause of death after lung cancer, is a public health issue in Western countries. Its incidence increases with age, with a mean age at diagnosis of 72 years.

There is much discussion regarding mass screening, with two recent international trials resulting in conflicting opinions on this subject $(1,2)$.

For the last 50 years, standard treatment for prostate cancer at the metastatic stage has been androgenic blockage with surgical and, in particular, chemical castration using LHRH

Correspondence to: Dr Nadine Houédé, Department of Medical Oncology, Institut Bergonié, 229 cours de l'Argonne, 33076 Bordeaux Cedex, France

E-mail: houede@bergonie.org

Key words: prostate, hormone-refractory, chemotherapy analogues. Although more than $80 \%$ of patients respond to this treatment (sometimes for prolonged periods), the evolution of the disease, on average 24-36 months, is always towards hormone resistance. This is generally identified by recurrence of an elevation in prostate-specific antigen (PSA) levels and/or the appearance of clinical symptoms.

The addition of an antiandrogenic agent, constituting a complete androgenic blockage (CAB), sometimes enables achievment of a new response. Following this, cessation of the antiandrogenic agent (called the withdrawal effect) induces a new biological response for a period of 6-8 months in $30 \%$ of cases. Yet, prostate cancer becomes hormone refractory as the disease progresses, despite these secondary hormonal manoeuvres. In the hormone-refractory phase, mean survival is 20 months (12).

The prognosis for hormone-refractory prostate cancer (HRPC) is associated with performance status, progression of the disease and damage to internal organs or to numerous bone sites, the presence of bone pain, the Gleason score and levels of LDH, alkaline phosphatase and haemoglobin $(3,4)$.

Prostate cancer has long been considered chemoresistant. A review of 26 trials conducted between 1988 and 1991 found a rate of response to chemotherapy of $8.7 \%$ (5). However, with a clear predominance of localisation in bone, which is not measurable, the assessment criteria for response to chemotherapy have been difficult to define.

In 1989, Fero et al (6) were the first to report that the change in PSA level may be used as an indicator of response to treatment in patients included in clinical trials. Several trials (7-9), and in particular a retrospective assessment of the SWOG 99-16 study (10), revealed a significant correlation between survival and a more than $50 \%$ decrease in PSA levels with treatment. This indicated the use of the PSA level as a good 'surrogate' marker in patient follow-up. Monitoring PSA levels has enabled the detection of the appearance of androgen-independent agents at a much earlier, often clinically asymptomatic, stage. Yet, it has also become more and more important to consider the effects of treatment on the quality of life as well as bone pain, in addition to the impact on lesions which are measurable using classic techniques and which are only present in $20 \%$ of patients. In order to reach a consensus regarding criteria relevant to the response to treatment, Bubley et al (11) proposed criteria for eligibility and response to treatment, which were used in trials concerning HRPC in 1999. These criteria have been redefined recently (12). 
Eligibility criteria are based on demonstrating that the disease is progressive, and this is defined using three factors, in combination or not: i) progression of lesions, which can be measured using classic techniques; ii) scintigraphic progression (at least two new lesions on the scintigram); and iii) progression of PSA levels (the authors suggest that two successive measurements of PSA levels be taken, with a value of $>5 \mathrm{ng} / \mathrm{ml}$ ).

Regarding criteria for response or progression, a decrease in PSA levels is considered to be significant when it is more than $50 \%$ of the baseline with confirmation more than 4 weeks later. Progression is defined as an increase of more than $25 \%$ in the PSA level compared to the baseline, which is also confirmed by a second measurement.

For many decades, a great number of anticancer agents have been tested for the treatment of HRPC. Several periods have been identified: i) the 'pre-PSA' era, where methodology and data collected from patients, who differed from present patients, are difficult to interpret; and ii) the 'post-PSA' era, when the use of two drugs predominated: mitoxantrone, related to anthracyclines, and more recently, docetaxel.

In 2004, when two large trials were underway involving the use of docetaxel as a first-line treatment for HRPC $(13,14)$, the Genitourinary Cancer Disease Site Group of the Cancer Care Ontario Program in Evidence-Based Care (CCOPEBC) carried out a review of the literature from 1966 to 2004 (15) and identified approximately 80 clinical trials involving various non-hormonal treatments for HRPC. Twenty-seven trials which randomized more than 50 patients were short-listed and analyzed. Between 1979 and 2001, six trials assessed the effectiveness of estramustine and found no improvement in tumour response rate or in overall survival. Three of these six trials, however, found a significant response rate in terms of PSA, but substantial toxicity at the digestive and cardiovascular levels (16,17 and Berry W, et al, Proc Am Soc Clin Oncol 20: abs 175, 2001). In 2004, one trial assessed the effectiveness of vinorelbine in 414 patients (18) without demonstrating a difference in terms of overall survival, while the clinical benefit (measured by the change in the performance status of the analgesic scale) was significantly better in this group (30.6 vs. 19.2\%, p=0.008). Between 1996 and 2002, three main trials assessed mitoxantrone. Based on the findings of these studies, mitoxantrone was defined as the standard first-line treatment before the docetaxel era. In addition, Kantoff et al (19) randomized 242 patients between an group with prednisone alone and an group with prednisone + $14 \mathrm{mg} / \mathrm{m}^{2}$ mitoxantrone. No difference was found in overall patient survival, but a difference was noted in the level of PSA response and a longer mean time to progression (8.1 vs. 4.1 months, $\mathrm{p}=0.018$ ). Berry et al (20) also found a difference in favour of the group administered mitoxantrone in terms of PSA response and time to progression. Finally, Tannock et al published the results of a randomized trial (21) comparing treatment with prednisone alone and prednisone with $12 \mathrm{mg} /$ $\mathrm{m}^{2}$ mitoxantrone in 161 patients. The main judgement criteria was effectiveness in reducing pain and a decrease in analgesics. An advantage was found in the group which combined prednisone and mitoxantrone, with a duration of response in terms of a decrease in pain of 42 vs. 18 weeks, $p<0.0001$, and a palliative benefit in $38 \%$ of the patients treated vs. $21 \%$ in controls $(\mathrm{p}=0.025)$.
In 2004, as the CCOPEBC carried out their literature review, two large Phase III trials, TAX 327 (13) and SWOG 99-16 (12), enabled docetaxel to be defined as the new standard first-line treatment for HRPC. In the first study, Tannock et al (13) randomized 1,006 patients. One group received $75 \mathrm{mg} / \mathrm{m}^{2}$ docetaxel i.v. every 3 weeks, the second, $30 \mathrm{mg} / \mathrm{m}^{2}$ docetaxel weekly, and the third, $12 \mathrm{mg} / \mathrm{m}^{2}$ mitoxantrone. All patients also received $5 \mathrm{mg}$ prednisone per os twice a day. A significant improvement in mean survival was found (18.9 vs. 16.5 months, $\mathrm{p}=0.009$ ) in the group treated with $75 \mathrm{mg} / \mathrm{m}^{2}$ docetaxel every 3 weeks, as well as a better response in terms of pain (35 vs. $22 \%, \mathrm{p}=0.01)$. The second trial by Petrylak et al (12) randomized 666 patients. One group received docetaxel plus estramustine and another group, mitoxantrone and prednisone. In the docetaxel plus estramustine group, the mean survival was significantly increased ( 17.5 vs. 15.6 months, $p=0.02)$. In both trials, the PSA response rate was also significantly better in the group treated with docetaxel.

Regarding the use of anthracyclines, a review of the literature in 2008 by Petrioli et al (22) found 38 Phase II and 13 Phase II-III randomized trials. The first trials assessing anthracyclines for first-line treatment in HRPC date back to the 1980s, and objective response rates were found to increase by more than $38 \%(23,24)$, with the majority of patients reporting an improvement in bone pain. In 1993, a Phase II randomized trial (25) comparing the administration of $25 \mathrm{mg} /$ $\mathrm{m}^{2}$ doxorubicin weekly and $30 \mathrm{mg} / \mathrm{m}^{2}$ epirubicin weekly found a PSA response of 14.8 and $20 \%$, respectively, as well as a decrease in pain in 33.3 and $37.7 \%$ of cases. Another study by these same authors carried out in 2002 (26) confirmed the palliative effects of weekly epirubicin with a reduction in pain symptoms in $56 \%$ of patients and an improvement in the quality of life in $68 \%$ of the 131 patients assessed. Two other studies found a decrease of more than $50 \%$ in the PSA levels in $81 \%$ of patients (27) and a decrease in bone pain in more than $65 \%$ of patients (28), respectively, demonstrating the activity of anthracyclines in prostate cancer. However, the majority of these trials assessing anthracyclines alone found mean survival rates of 5-13 months, similar to those found in untreated patients.

Between 1984 and 1998, several trials assessed anthracyclines in combination in metastatic HRPC (29-31). The majority of these trials was carried before the era of PSA level detection. The data available were limited. No study found any advantage in overall survival, and only two carried out statistical comparisons in terms of the tumour response rate. One of these trials, carried out in 1992 by Laurie et al (29), reported an improvement in survival with chemotherapy combining 5FU, doxorubicin and mitomycin $\mathrm{C}$ as compared to the same agents administered as sequential treatment (8.7 vs. 7.1 months, $\mathrm{p}=0.025$ ).

Several studies also assessed the effectiveness of doxorubicin combined with cyclophosphamide. In 1984, Stephens et al (30) compared a combination of $40 \mathrm{mg} / \mathrm{m}^{2}$ doxorubicin $+200 \mathrm{mg} / \mathrm{m}^{2}$ cyclophosphamide every 3 weeks to $3,600 \mathrm{mg} / \mathrm{m}^{2}$ hydroxyurea per os. The tumour response rate was $32 \%$ in the group with the combination vs. $4 \%$ in the group with hydroxyurea. In 1992, Saxman et al (31) compared doxorubicin + cyclophosphamide + methotrexate vs. cyclophosphamide alone, with a tumour response rate of $18.8 \%$ in 
Table I. Characteristics of the patients treated with miniMAID protocol.

\begin{tabular}{lccccc}
\hline $\begin{array}{l}\text { Patient } \\
\text { no. }\end{array}$ & $\begin{array}{c}\text { Age at diagnosis } \\
\text { (years) }\end{array}$ & $\begin{array}{c}\text { Gleason } \\
\text { score }\end{array}$ & $\begin{array}{c}\text { TNM stage } \\
\text { at diagnosis }\end{array}$ & $\begin{array}{c}\text { Initial PSA } \\
\text { levels }\end{array}$ & Initial treatment \\
\hline 1 & 52 & $8(4+4)$ & T3 N1 Mx & 9.1 & H, 10 months \\
2 & 60 & $7(3+4)$ & Tx N+ Mx & & 3rd line \\
3 & 54 & 8 & T3b N2 Mx & 73.0 & H, 24 months $+\mathrm{R}$ \\
4 & 61 & 7 & T4 N+ M+ & 435.0 & H, 27 months + R \\
5 & 62 & $\mathrm{X}$ & T3b N1 M+ & 1.4 & H, 13 months + R \\
6 & 56 & 9 & Tx N+ & 16.0 & H, 9 months line \\
7 & 54 & 6 & T3b N0 M0 & 26.6 & P + R + H, 93 months line \\
\hline
\end{tabular}

$\mathrm{H}$, hormone therapy; $\mathrm{P}$, prostatectomy; R, radiotherapy.

the combination treatment group vs. $6 \%$ in the other group. The majority of these combination trials found significant toxicity, with more than $20 \%$ grade 3-4 neutropenia (31).

\section{Patients and methods}

In the present study, we report our experience with the use of doxorubicin and ifosfamide in 7 patients treated in the nth line for hormone-refractory cancer between 2006 and 2008. The characteristics at diagnosis of these 7 patients are shown in Table I.

Mean age at diagnosis was 57 years. Six patients who were at a locally advanced stage at the time of diagnosis $(\mathrm{N}+, 2)$ had previously undergone a prostatectomy. The 'miniMAID' protocol consisted of administration over 3 days of $20 \mathrm{mg} /$ $\mathrm{m}^{2}$ doxorubicin per day and $1-1.5 \mathrm{mg} / \mathrm{m}^{2}$ ifosfamide per day associated with Uromitexan, renewed every 3 weeks.

\section{Results}

Efficacy. Patient no. 1 received the miniMAID protocol in the third line after 10 months of hormone therapy, 3 cycles of Taxotere with progression in the form of carcinomatous meningitis (treated with intrathecal injections of methotrexate and radiotherapy) and 6 cycles of carboplatin. The PSA level prior to treatment was 327 . The targets were mediastinal (the largest measuring $25 \mathrm{~mm}$ ), right subclavicular, celiomesenteric, bilateral iliac and left inguinal lymph nodes. After 3 cycles, a scan showed stability of the target nodes, but with biological (PSA, 646) and scintigraphic progression (a new fixation at the level of the left tibial diaphysis associated with aggravation of the existing diffuse hyperfixations). The patient succumbed 3 months after the third cycle.

Patient no. 2 received the miniMAID protocol in the third line (with $1 \mathrm{mg} / \mathrm{m}^{2}$ ifosfamide per day) after 8 months of hormone therapy, 9 cycles of Taxotere, 2 cycles of carboplatin and a clear aggravation in the bone scintigram. The targets were mediastinal, lateroaortic, celiomesenteric and portocaval lymph nodes, as well as three hepatic lesions, 7, 12 and $10 \mathrm{~mm}$ in size. Assessment after 3 cycles found biological stabilization (PSA, 38.6) and a significant response from mediastinal lymph node targets, as well as stability of hepatic and abdominal targets. Assessment after 6 cycles found a biological response
(PSA, 5.7), stability after scan and scintigraphic improvement. Secondary prophylaxis with $50 \mathrm{mg}$ /day Endoxan was then started with a response maintained for 3 months, after which the patient received oral etoposide for 3 months. The patient succumbed 9 months after the last cycle.

Patient no. 3 received the miniMAID protocol in the fourth line after 24 months of hormone therapy, 9 cycles of Taxotere, 6 months treatment with Endoxan per os, 4 months of carboplatin, with an evident biological and clinical progression (appearance of brain metastases treated surgically and with radiotherapy). PSA was then at 329 . The CT scan found measurable lymph node targets and diffuse bone lesions, for which he had already received radiotherapy in the spinal column (R3 and R4) and left shoulder. After the second cycle, a clinical response was observed with a decrease in the consumption of analgesics. The patient presented subcutaneous inflammation around the implantable infusion pump with neutropenia, justifying hospitalization and removal of the pump. Assessment after 4 cycles found biological stability (PSA, 379), but progression in target tumours. Despite starting treatment with Xeloda, the patient succumbed 2 months after the fourth and last miniMAID cycle.

Patient no. 4 received the miniMAID protocol in the fourth line after 27 months of hormone therapy, more than 1 year of oral chemotherapy with Navelbine, 9 cycles of Taxotere, 3 cycles of carboplatin; in total, approximately 6 years of treatment after the initial diagnosis of a disease, which was metastatic from the outset in bone and lymph nodes. The PSA level was at that time 4,421 . The CT scan found mediastinal and retroperitoneal target nodes. Scintigraphy showed that numerous hyperfixing sites had appeared with carboplatin. After 3 cycles there was a biological response (PSA, 2,800) and a clinical benefit as far as pain was concerned. After 6 cycles, the outcome was a biological response (PSA, 2,571) and stabilization of target tumours and bone scintigram. The patient succumbed after presenting carcinomatous meningitis 2 months after the last cycle.

Patient no. 5 received the miniMAID protocol in the fifth line after 6 cycles of Taxotere, 2 months of Endoxan, 2 cycles of carboplatin and 3 cycles of Novantrone. The PSA level was 330 at the beginning of treatment. There were mediastinal and retroperitoneal target nodes. After 3 cycles, the PSA level was at 427 , but bone scintigraphy showed tumour stability. It was 
Table II. Assessments at the third or fourth cycle.

\begin{tabular}{|c|c|c|c|c|c|}
\hline $\begin{array}{l}\text { Patient } \\
\text { no. }\end{array}$ & $\begin{array}{l}\text { Pre MAID } \\
\text { PSA levels }\end{array}$ & $\begin{array}{l}\text { Location of } \\
\text { metastases }\end{array}$ & PSA levels & CT scan & Scintigraphy \\
\hline 1 & 327 & $\begin{array}{l}\text { Diffuse - bone } \\
\text { Diffuse - lymph nodes }\end{array}$ & Progression (646) & Stability & Progression \\
\hline 2 & 39 & $\begin{array}{l}\text { Diffuse - bone } \\
\text { Diffuse - lymph nodes } \\
\text { Three hepatic locations }\end{array}$ & Stability (38.6) & Response & \\
\hline 3 & 329 & $\begin{array}{l}\text { Diffuse - bone } \\
\text { Diffuse - lymph nodes }\end{array}$ & Stability (379) & Progression & \\
\hline 4 & 4,421 & $\begin{array}{l}\text { Diffuse - bone } \\
\text { Diffuse - lymph nodes }\end{array}$ & Response $(2,800)$ & & \\
\hline 5 & 330 & $\begin{array}{l}\text { Diffuse - bone } \\
\text { Diffuse - lymph nodes }\end{array}$ & Progression (427) & & Stability \\
\hline 6 & 24 & $\begin{array}{l}\text { Bone and lymph nodes } \\
\text { Peritoneal carcinomatosis }\end{array}$ & Response (7.5) & Response & \\
\hline 7 & 11,874 & $\begin{array}{l}\text { Bone and lymph nodes } \\
\text { Diffuse hepatic infiltration }\end{array}$ & Stability $(12,593)$ & Stability & \\
\hline
\end{tabular}

Table III. Assessment at the sixth cycle.

\begin{tabular}{|c|c|c|c|c|}
\hline Patient no. & PSA levels & CT scan & Scintigraphy & Conclusion after 6 cycles \\
\hline \multicolumn{5}{|l|}{1} \\
\hline 2 & Response (5.7) & Stability & Response & $\begin{array}{l}\text { Biological and scintigraphic response } \\
\text { Stability CAT scan }\end{array}$ \\
\hline \multicolumn{5}{|l|}{3} \\
\hline 4 & Response $(2,571)$ & Stability & Stability & $\begin{array}{l}\text { Biological response } \\
\text { Stability scintigraphy and CAT scan }\end{array}$ \\
\hline 5 & Progression & Progression & Progression & \\
\hline 6 & Response (4.1) & Response & & Biological and CAT scan response \\
\hline
\end{tabular}

decided to continue treatment for up to 6 cycles. At the end of the treatment, CT scan assessment showed a progression of bone and lymph node targets. The PSA level was 399. The patient succumbed 6 months after the last cycle.

Patient no. 6 also received the miniMAID protocol in the fifth-line treatment after 5 cycles of Taxotere, 6 cycles of carboplatin and etoposide, 8 months of Celltop per os at $50 \mathrm{mg} /$ day and 10 months of Endoxan per os at $50 \mathrm{mg} /$ day. The PSA level was 24. The CT scan found target nodes as well as peritoneal carcinomatosis, with a $66-\mathrm{mm}$ right pararenal mass and a 45-mm retroperitoneal mass. After 3 cycles there was a biological (PSA, 7.3) and a tumoral response, with a decrease in target nodes. It should be noted that this patient had an episode of febrile aplasia in the second cycle with grade 4 neutropenia (leukocytes at $100 / \mathrm{mm}^{3}$ ), justifying a short hospitalization for the administration of of antibiotic treatment and monitoring. After 6 cycles, a tumoral response was maintained with a new overall decrease in node formation of $13 \%$. The PSA level was 4.1 at the end of the treatment. After 3 months with no treatment, there was tumour stability and a PSA of 6. Five months after the last cycle, faced with biological progression, a sixth-line treat- ment with Xeloda was instituted. The patient succumbed 4 months later.

The last patient, no. 7 , received the miniMAID protocol in the seventh line, more than 13 years after the initial diagnosis of locally advanced cancer and after 93 months of hormone therapy, 3 cycles of Endoxan, 8 cycles of Taxotere, then Distilbene for nearly 15 months, Navelbine, 3 cycles of carboplatin, Celltop for 3 months, without any response, and inclusion in a Phase I trial to assess Enzastaurin. Assessment at 2 months showed an increase in hepatic infiltrate and progression in retroperitoneal target nodes of $27 \%$, justifying exit from the trial. He was then offered the miniMAID protocol. Although early assessment after 2 cycles showed biological (PSA, 12,593) and CT scan stability, the patient presented a cave syndrome near the end of the third cycle, justifying cessation of chemotherapy. He was then put back on Distilbene with an interesting clinical and biological response (PSA 9,336 at 2 months). He is currently on Xeloda and has been since March 2009.

Collectively, this treatment enabled us to obtain three biological responses in the 7 patients treated, as well as one $\mathrm{CT}$ scan response, one bone scan response and two CT scan 
Table IV. History of the disease.

\begin{tabular}{llllll}
\hline $\begin{array}{l}\text { Patient } \\
\text { no. }\end{array}$ & $\begin{array}{c}\text { Start of hormone } \\
\text { therapy }\end{array}$ & \multicolumn{1}{c}{$\begin{array}{c}\text { Start of } \\
\text { chemotherapy }\end{array}$} & Start miniMAID & \multicolumn{1}{c}{ Death } & $\begin{array}{c}\text { Overall survival to hormone } \\
\text { refractory stage (months) }\end{array}$ \\
\hline 1 & Beginning 2004 & July 2005 & March 2006 & August 2006 & 13 \\
2 & July 2004 & October 2005 & September 2006 & October 2007 & 24 \\
3 & September 2004 & September 2006 & June 2008 & October 2008 & 25 \\
4 & August 2002 & September 2005 & May 2008 & November 2008 & 38 \\
5 & October 2005 & May 2007 & April 2008 & January 2009 & 20 \\
6 & September 2004 & August 2005 & April 2008 & January 2009 & 41 \\
7 & Mid-1995 & Beginning 2007 & September 2008 & Still alive & $>24$ \\
\hline
\end{tabular}

stabilizations with regard to imaging examinations (Tables I and III). Mean duration of survival from the beginning of treatment with chemotherapy was calculated to be more than 26 months, with a variance of 13 months at more than 41 months (Table IV). Mean duration of survival from the start of the miniMAID protocol was calculated to be 6.6 months. There was a good correlation between the biological response measured by the PSA level and tumour response assessed clinically and by imaging techniques.

Toxicity. All of the patients in this cohort had cardiac assessment with ultrasound and measurement of the left ventricle ejection fraction before treatment began. On retrospective analysis of the data, no cardiac toxicity was reported. All patients had haematopoietic leukocyte growth factor support during the inter-cycle periods. Two episodes of febrile aplasia justifying hospitalization were reported in 2 patients; one rapidly resolved without complication towards the end of the second cycle; the other, also related to cellulitis, was resolved towards the end of the second cycle. The majority of patients had support in the form of packed red blood cell transfusion. It was difficult to balance medullary deficiency through tumour invasion with direct haematological toxicity from the drugs used.

\section{Discussion}

Treatment of HRPC has seen great advances over the last 20 years, in particular improvements in assessing the response to treatment by measuring PSA levels.

Docetaxel is considered to be the chemotherapy of choice in first-line treatment, as data concerning other possible treatments are sparse and, though sometimes encouraging, often outdated and difficult to apply, and in any case not standardized from the second line of treatment.

Anthracyclines are among the most important anticancer agents with a wide spectrum of antitumoral activity. Anthracyclines may also induce apoptosis in prostate cancer cells expressing the bcl-2 oncogene. The activity of anthracyclines in prostate cancer has already been demonstrated (22-28,30,31).

Cyclophosphamide is a drug which has also shown activity in prostate cancer, in particular, metronomic per os and in cycles. Ifosfamide, an analogue of cyclophosphamide, is an alkylating intercalator agent which interacts directly with DNA, resulting in cell death by apoptosis. It appears to be more effective than cyclophosphamide, in particular in the treatment of sarcoma, where it has been most extensively studied (32).

In addition, a synergistic effect in combining this alkylating agent with anthracyclines has been noted (33). To our knowledge, there is little data concerning the use of this drug in the treatment of HRPC. Some phase II trials, consisting of less than 30 patients, have shown mixed results $(34,35)$.

More recently, studies have assessed the combination of anthracyclines and taxanes, and have demonstrated promising results. For example, a weekly combination of $30 \mathrm{mg} / \mathrm{m}^{2}$ epirubicin plus $30 \mathrm{mg} / \mathrm{m}^{2}$ docetaxel in 38 patients achieved a decrease in PSA levels in $68.4 \%$ of cases and a decrease in pain in $72.7 \%$ of cases (36).

Although the present study was a retrospective analysis of a small number of patients, it emphasizes several important points in the history of prostate cancer. Prostate cancer has long been considered to not be sensitive to chemotherapy. Due to this fact, response criteria must be defined that are different from those of other tumour types. The responses found in this cohort of patients in nth-line treatment demonstrate the chemosensitivity of this cancer. Although a consensus has been made with regard to first-line treatment with docetaxel based on its benefit in overall survival in two large wellconducted studies, from the second line onwards no notable result has been found. However, other available drugs, when administered sequentially in clinical practice to patients in overall good physical condition, show an incidental activity on survival. Our cohort of patients, directly $\mathrm{N}+$, having had up to 7 lines of chemotherapy and with a mean survival of more than 26 months from the institution of chemotherapy, is one example. Of course, the patients were relatively young, with a general state that permitted this incisive treatment.

The majority of trials using anthracyclines in association with cyclophosphamide were carried out before the use of surrogate response markers, such as PSA levels, and with questionable methodologies. The rate of response found in our cohort treated in the nth line suggests that anthracyclines used in combination with ifosfamide may have a much greater activity than that demonstrated previously. This promising result requires further investigation and verification with Phase II trials. 
In conclusion, metastatic HRPC is characterized in more than $80 \%$ of cases by bone damage causing pain, the objective assessment of which is difficult. Over the last few years, appropriate assessment criteria have emerged.

Docetaxel is the standard chemotherapy in first-line treatment, but there is a wide panel of classic drugs available which, when used in combination, are potentially effective. At present, after first-line treatment, two paths are evident: i) to develop new protocols for combined chemotherapy, or ii) to turn to new types of treatment, such as anti-angiogenics, or treatments more specific to bone damage, such as inhibitors of the receptor of endothelin A. These multiple options emphasize the growing complexity of the management of prostate cancer and the need to include patients in clinical trials. Assessment of anthracyclines in combination with ifosfamide in a prospective second-line treatment trial after failure of docetaxel is warranted.

\section{References}

1. Schröder FH, Hugosson J, Roobol MJ, Tammela TL, Ciatto S, Nelen V, Kwiatkowski M, Lujan M, Lilja H, Zappa M, Denis LJ, Recker F, Berenguer A, Määttänen L, Bangma $\mathrm{CH}$, Aus G, Villers A, Rebillard X, van der Kwast T, Blijenberg BG, Moss SM, de Koning HJ, Auvinen A and ERSPC Investigators: Screening and prostate-cancer mortality in a randomized European study. N Engl J Med 13: 1320-1328, 2009.

2. Andriole GL, Crawford ED, Grubb RL III, Buys SS, Chia D, Church TR, Fouad MN, Gelmann EP, Kvale PA, Reding DJ, Weissfeld JL, Yokochi LA, O'Brien B, Clapp JD, Rathmell JM, Riley TL, Hayes RB, Kramer BS, Izmirlian G, Miller AB, Pinsky PF, Prorok PC, Gohagan JK, Berg CD and PLCO Project Team: Mortality results from a randomized prostate-cancer screening trial. N Engl J Med 13: 1310-1319, 2009.

3. Vollmer RT, Kantoff PW, Dawson NA and Vogelzang NJ: A prognostic score for hormone-refractory prostate cancer: analysis of two Cancer and Leukemia Group B studies. Clin Cancer Res 5: 831-837, 1999.

4. Halabi S, Small EJ, Kantoff PW, Kattan MW, Kaplan EB, Dawson NA, Levine EG, Blumenstein BA and Vogelzang NJ: Prognostic model for predicting survival in men with hormonerefractory metastatic prostate cancer. J Clin Oncol 21: 1232-1237, 2003.

5. Yagoda A and Petrylak D: Cytotoxic chemotherapy for advanced hormone-resistant prostate cancer. Cancer 71: 1098-1109, 1993.

6. Ferro MA, Gillatt D, Symes MO and Smith PJ: High-dose intravenous estrogen therapy in advanced prostatic carcinoma. Use of serum prostate-specific antigen to monitor response. Urology 34 134-138, 1989.

7. Smith DC, Dunn RL, Strawderman MS and Pienta KJ: Change in serum prostate-specific antigen as a marker of response to cytotoxic therapy for hormone-refractory prostate cancer. J Clin Oncol 16: 1835-1843, 1998.

8. Kelly WK, Scher HI, Mazumdar M, Vlamis V, Schwartz M and Fossa SD: Prostate-specific antigen as a measure of disease outcome in metastatic hormone-refractory prostate cancer. J Clin Oncol 11: 607-615, 1993.

9. Scher HI, Kelly WM, Zhang ZF, Ouyang P, Sun M, Schwartz M, Ding C, Wang W, Horak ID and Kremer AB: Post-therapy serum prostate-specific antigen level and survival in patients with androgen-independent prostate cancer. J Natl Cancer Inst 91: 244-251, 1999.

10. Petrylak DP, Ankerst DP, Jiang CS, Tangen CM, Hussain MH, Lara PN Jr, Jones JA, Taplin ME, Burch PA, Kohli M, Benson MC, Small EJ, Raghavan D and Crawford ED: Evaluation of prostatespecific antigen declines for surrogacy in patients treated on SWOG 99-16. J Natl Cancer Inst 98: 516-521, 2006.

11. Bubley GJ, Carducci M, Dahut W, et al: Eligibility and response guidelines for phase II clinical trials in androgen-independent prostate cancer: recommendations from the Prostate-Specific Antigen Working Group. J Clin Oncol 17: 3461-3467, 1999.

12. Scher HI, Halabi S, Tannock I, et al: Prostate Cancer Clinical Trials Working Group: design and end points of clinical trials for patients with progressive prostate cancer and castrate levels of testosterone: recommendations of the Prostate Cancer Clinical Trials Working Group. J Clin Oncol 26: 1148-1159, 2008.
13. Petrylak DP, Tangen CM, Hussain MH, Lara PN Jr, Jones JA, Taplin ME, Burch PA, Berry D, Moinpour C, Kohli M, Benson MC, Small EJ, Raghavan D and Crawford ED: Docetaxel and estramustine compared with mitoxantrone and prednisone for advanced refractory prostate cancer. N Engl J Med 351: 1513-1520, 2004.

14. Tannock IF, de Wit R, Berry WR, Horti J, Pluzanska A, Chi KN, Oudard S, Théodore C, James ND, Turesson I, Rosenthal MA, Eisenberger MA and TAX 327 Investigators: Docetaxel plus prednisone or mitoxantrone plus prednisone for advanced prostate cancer. N Engl J Med 351: 1502-1512, 2004.

15. Winquist E, Waldron T, Berry S, Ernst DS, Hotte S and Lukka H: Non-hormonal systemic therapy in men with hormone-refractory prostate cancer and metastases: a systematic review from the Cancer Care Ontario Program in Evidence-based Care's Genitourinary Cancer Disease Site Group. BMC Cancer 6: 112, 2006.

16. Hudes G, Einhorn L, Ross E, Balsham A, Loehrer P, Ramsey H, Sprandio J, Entmacher M, Dugan W, Ansari R, Monaco F, Hanna M and Roth B: Vinblastine versus vinblastine plus oral estramustine phosphate for patients with hormone-refractory prostate cancer: a Hoosier Oncology Group and Fox Chase Network phase III trial. J Clin Oncol 17: 3160-3166, 1999.

17. Iversen P, Rasmussen F, Asmussen C, Christensen IJ, Eickhoff J, Klarskov P, Larsen E, Mogensen P, Mommsen S and Rosenkilde P: Estramustine phosphate versus placebo as second line treatment after orchiectomy in patients with metastatic prostate cancer: DAPROCA study 9002. Danish Prostatic Cancer Group. J Urol 157: 929-934, 1997.

18. Abratt RP, Brune D, Dimopoulos MA, Kliment J, Breza J, Selvaggi FP, Beuzeboc P, Demkow T and Oudard S: Randomised phase III study of intravenous vinorelbine plus hormone therapy versus hormone therapy alone in hormone-refractory prostate cancer. Ann Oncol 15: 1613-1621, 2004.

19. Kantoff PW, Halabi S, Conaway M, Picus J, Kirshner J, Hars V, Trump D, Winer EP and Vogelzang NJ: Hydrocortisone with or without mitoxantrone in men with hormone-refractory prostate cancer: results of the Cancer and Leukemia Group B 9182 study. J Clin Oncol 17: 2506-2513, 1999.

20. Berry W, Dakhil S, Modiano M, Gregurich M and Asmar L: Phase III study of mitoxantrone plus low dose prednisone versus low dose prednisone alone in patients with asymptomatic hormone refractory prostate cancer. J Urol 168: 2439-2443, 2002.

21. Tannock IF, Osoba D, Stockler MR, Ernst DS, Neville AJ, Moore MJ, Armitage GR, Wilson JJ, Venner PM, Coppin CM and Murphy KC: Chemotherapy with mitoxantrone plus prednisone or prednisone alone for symptomatic hormone-resistant prostate cancer: a Canadian randomized trial with palliative end points. J Clin Oncol 14: 1756-1764, 1996.

22. Petrioli R, Fiaschi AI, Francini E, Pascucci A and Francini G: The role of doxorubicin and epirubicin in the treatment of patients with metastatic hormone-refractory prostate cancer. Cancer Treat Rev 34: 710-718, 2008.

23. Torti FM, Aston D, Lum BL, Kohler M, Williams R, Spaulding JT, Shortliffe L and Freiha FS: Weekly doxorubicin in endocrine-refractory carcinoma of the prostate. J Clin Oncol 1: 477-482, 1983.

24. Delaere KP, Leliefeld H, Peulen F, Stapper EW, Smeets J and Wils J: Phase II study of epirubicin in advanced hormoneresistant prostatic carcinoma. Br J Urol 70: 641-642, 1992.

25. Francini G, Petrioli R, Manganelli A, Cintorino M, Marsili S, Aquino A and Mondillo S: Weekly chemotherapy in advanced prostatic cancer. Br J Cancer 67: 1430-1436, 1993.

26. Petrioli R, Fiaschi AI, Pozzessere D, Messinese S, Sabatino M, Marsili S, Correale P, Manganelli A, Salvestrini F and Francini G: Weekly epirubicin in patients with hormone-resistant prostate cancer, Br J Cancer 87: 720-725, 2002.

27. Neri B, Barbagli G, Bellesi P, Di Loro R, Lombardi V, Lombardo C, Magrini T, Mottola A, Nicita G, Palminteri E, Ponchietti R, Raugei A and Intini C: Weekly epidoxorubicin therapy in hormone-refractory metastatic prostate cancer. Anticancer Res 17: 3817-3820, 1997.

28. Van Andel G, Fernandez de Moral P, Caris CT, Carpentier P, Wils J, de Bruin MJ, Witjes JA, Debruyne FM and Witjes WP: A randomized study comparing epirubicin in a 4-weekly versus a weekly intravenous regimen in patients with metastatic, hormone resistant, prostatic carcinoma: effects on health related quality of life. World J Urol 21: 177-182, 2003.

29. Laurie JA, Hahn RG, Therneau TM, Patel SR, Mailliard JA, Windschitl HE, Twito DI, Morton RF and Krook JE: Chemotherapy for hormonally refractory advanced prostate carcinoma. A comparison of combined versus sequential treatment with mitomycin $\mathrm{C}$, doxorubicin, and 5-fluorouracil. Cancer 69: 1440-1444, 1992. 
30. Stephens RL, Vaughn C, Lane M, Costanzi J, O'Bryan R, Balcerzak SP, Levin H, Frank J and Coltman CA Jr: Adriamycin and cyclophosphamide versus hydroxyurea in advanced prostatic cancer. A randomized Southwest Oncology Group study. Cancer 53: 406-410, 1984

31. Saxman S, Ansari R, Drasga R, Miller M, Wheeler B, McClean J and Einhorn L: Phase III trial of cyclophosphamide versus cyclophosphamide, doxorubicin, and methotrexate in hormonerefractory prostatic cancer. A Hoosier Oncology Group Study. Cancer 70: 2488-2492, 1992.

32. Bramwell VH, Mouridsen HT, Santoro A, et al: Cyclophosphamide versus ifosfamide: a randomized phase II trial in adult soft-tissue sarcomas. The European Organization for Research and Treatment of Cancer [EORTC], Soft Tissue and Bone Sarcoma Group. Cancer Chemother Pharmacol 31 (Suppl 2): 180-184, 1993.

33. Blum RH, Edmonson J, Ryan L and Pelletier L: Efficacy of ifosfamide in combination with doxorubicin for the treatment of metastatic soft-tissue sarcoma. The Eastern Cooperative Oncology Group. Cancer Chemother Pharmacol 31 (Suppl 2): 238-240, 1993.
34. Hervonen Lehtinen T, Tammela TL and Kellokumpu-Lehtinen P: A randomised dose finding phase II study on ifosfamide in metastatic hormone-refractory prostate cancer (HRPC). J Exp Clin Cancer Res 21: 177-180, 2002.

35. Williamson SK, Wolf MK, Eisenberger MA, O'Rourke MA, Brannon W and Crawford ED: Phase II evaluation of ifosfamide/ mesna in metastatic prostate cancer. A Southwest Oncology Group study. Am J Clin Oncol 19: 368-370, 1996.

36. Petrioli R, Paolelli L, Francini E, Manganelli A, Salvestrini F and Francini G: Weekly docetaxel and epirubicin in treatment of advanced hormone-refractory prostate cancer. Urology 69: 142-146, 2007. 